\title{
Os antigos reis de Israel e o Mosteiro de San Lourenzo El Real del Escorial
}

\author{
Camila Cristina Souza Lima ${ }^{7}$ \\ DOI 10.20396/eha.vil4.3413
}

O monastério de San Lorenzo el Real del Escorial foi edificado por iniciativa do monarca Felipe II de Espanha (1527-1598) para ser sepultura digna de seu pai, o imperador Carlos V. Também deveria ser memória e comemoração da primeira vitória do novo governante na Batalha de San Quintin, ocorrida em 10 de agosto de 1557, dia do santo mártir espanhol São Lourenço. Seria, a partir do sepultamento de Carlos V, panteão real, última morada dos reis espanhóis. Era um monastério guardado pela Ordem exclusivamente ibérica de San Jerônimo, que cuidaria das orações pelas almas dos antigos monarcas.

Parte da memória construída sobre esse edifício deu especial ênfase para a relação entre o Escorial (nome mais sintético, pelo qual é mais conhecido) e o Templo de Salomão. Isso se deve, sobretudo, pelo fato de Juan de Herrera, mestre responsável por parte significativa das obras nessa fábrica durante o reinado de Felipe II, ter como auxiliar e discípulo Juan Bautista Villalpando (1552-1608), que depois escreveu sobre o templo de Salomão a partir da leitura do livro de Ezequiel, ilustrando também seu texto com reconstituições desse edifício sagrado ${ }^{2}$. Ainda que Herrera e o próprio Felipe II tivessem visto os desenhos realizados por Villalpando e que muitas vezes tenha se procurado encontrar no Escorial um edifício que emulasse o templo salomônico, a maneira como os contemporâneos às obras de Felipe II para esse monastério constroem seu discurso evocando o Antigo Testamento e alguns dos reis bíblicos deve ser pensada de forma mais cuidada. Trataremos sobre esse aspecto nas próximas páginas.

No complexo do Escorial, há uma fachada principal em cujo centro se encontra a entrada geral do edifício, por onde se pode acessar de forma mais direta a igreja. Em 1582, Felipe II ocupouse dessa entrada, firmando contrato com Juan Bautista Monegro (1545-1621) para realizar ali uma

\footnotetext{
1 Doutora em História e Fundamentos da Arquitetura e do Urbanismo, pela Faculdade de Arquitetura da Universidade de São Paulo (FAU-USP); mestre em História Social pela Faculdade de Filosofia, Letras e Ciências Humanas da Universidade de São Paulo (FFLCH-USP), com bolsa de pesquisa concedida pela FAPESP; bacharel e licenciada em História pela Faculdade de Filosofia, Letras e Ciências Humanas da Universidade de São Paulo (FFLCH-USP) e pela Faculdade de Educação da Universidade de São Paulo (FE-USP).

2 Juan Bautista Villalpando (1552-1608) pertencia à Companhia de Jesus e, depois de ter atuado como auxiliar de Juan de Herrera no Escorial, escreveu uma obra com Jerônimo Prado (1547-1595), também jesuíta, de exegese bíblica sobre as visões do profeta Ezequial em 3 tomos, publicados em Roma entre 1596 e 1604, considerando que o templo que o profeta descrevia em suas visões seria o Templo de Salomão. RUBIO, L. (O.S.A.). El tratado de Villalpando: origen, vicissitudes y contenido. In: VILLALPANDO, Juan Bautista. Tratado de Arquitectura Perfecta en la Última Visión de Ezequiel (trad. Frei Luciano Rubio O.S.A.). Madrid: Coléio Oficial de Arquitectos de Madrid, 1990, pp. 73-102.
} 
estátua de San Lorenzo, que ocuparia o nicho central e estaria em destaque para quem estivesse diante do edifício. A estátua de granito tem mãos, cabeça e pés esculpidos de mármore e o atributo do santo, uma grelha, em bronze dourado a fogo. Além da imagem do santo, a entrada tem o escudo de armas do rei (com armas de Castela, Leão, Aragão, Sicilia, Portugal, Borgonha e Brabante), com coroa imperial, indicando a presença de Carlos V no edifício, envolto no colar da Ordem do Toison de Oro ${ }^{3}$.

O frei José de Siguenza, em sua história sobre a construção do Monastério do Escorial, considera que a maneira como essas armas foram apresentadas na fachada, estando presentes apenas nesse local e nos sepulcros dos membros da família real, demonstrava a modéstia de Felipe II, dando maior destaque à imagem do patrono, São Lourenço ${ }^{4}$.

Ao atravessar essa entrada, há um pátio que marca uma preparação para a ingresso na igreja, uma espécie de transição entre o espaço externo e o espaço sacralizado. Esse pátio é conhecido como Pátio de los Reyes, porque nele se vê a fachada da igreja em que se destacam as estátuas de seis reis do Antigo Testamento. Esse pátio de medidas reduzidas é resultado dos desenhos de Herrera e de pareceres da Academia de Disegnio, em Florença, consultada em $1567^{5}$. As estátuas dos reis de Judá também foram realizadas por Juan Bautista de Monegro, com contrato firmado já em 1580, antes da fachada exterior. As imagens dos reis, assim como a de São Lourenço, têm os corpos de granito, com mãos, pés e cabeças em mármore branco, com coroas, cetros e emblemas em bronze dourado a fogo e foram colocadas na fachada em $1584 .^{6}$

Siguenza escolhe apresentar essa fachada da igreja, a primeira vista daqueles que adentram o complexo, para reforçar sua beleza e qualidade, sendo mostra da superação da arquitetura que se realizava até então porque foi realizada segundo os preceitos da Antiguidade Romana. Em suas palavras:

Luego, en poniendo los piés en los umbrales de la puerta principal, se comienza á descobrir una majestad grande y desusada en los edifícios de España, que habia tantos siglos que estaba sepultada en la barbárie ó grosería de los godos y árabes, que enseñorandose de ella por nuestros pecados, apenas nos dejaron luz de cosa buena, ni de primor, ni en las letras, ni en las artes. ${ }^{7}$

\footnotetext{
3 MARTÍN GONZÁLEZ, J. J. Interacción: arquitectura y escultura en El Escorial. In: JAVIER CAMPOS Y FERNÁNDEZ DE SEVILLA, F. (coord.). La escultura en el Monasterio del Escorial: Actas del Simposium. Madrid: Real Centro Universitario Escorial-María Cristina, 1994, págs.31-57.

4 SICUENZA, J. Historia primitiva y exacta del Monasterio del Escorial. Madrid: Imprenta y Fundación de M. Tello, impressor de Cámara de S.

M. Isabel la Católica, 1881. Fac-símile Valladolid: Editorial Maxtor, 2003, pp. 256-257

5 WILKINSON-ZERNER, C. Juan de Herrera: Arquitecto de Felipe II. Trad. Isabel Balsinde. Madrid: Ediciones Akal, 1996.

6 MARTÍN GONZÁLEZ, J. J. Op. cit. p.156-7.

7 SIGUENZA, J. Op. cit, p.264.
} 
Essa tópica servia para destacar e reforçar a importância do impacto dessa entrada, que deveria indicar a grandiosidade do todo do monastério.

Os reis presentes na fachada são, da esquerda para a direita de quem vê a igreja a partir da entrada do monastério: primeiramente o par Josafá e Ezequias; ao centro, com destaque, estão Davi e Salomão; e por fim, Josias e Manasés. Esses reis, nas palavras de Siguenza: "son seis Reyes del Viejo Testamento, de la tribu de Judá y família de David, los más pios de aquella genealogia, y que tuvieron alguna parte en aquel templo famoso que quiso Dios se le hiciese en aquel pueblo"8

A imagem da piedade desses reis e da ligação familiar entre eles, no local que serviria de panteão dinástico dos Habsburgos espanhóis, reforça a ideia de que a igreja se constrói em pedra e nas ações dos homens. Homens pios podem construir obras pias, o que é especialmente esperado dos reis. Assim, a imagem da piedade de Felipe II é reforçada nas estátuas dos antigos reis de Judá colocadas na fachada da igreja como exemplos a serem emulados e memória retomada na edificação do Escorial. Felipe II pôde construir um templo digno para honrar a Deus porque se colocou como defensor da Igreja Católica em tempos de quebra da cristandade com as reformas religiosas, porque contribuía para a difusão do cristianismo pelo mundo em suas colônias, nesse momento acrescidas em seus domínios pelas colônias portuguesas após a União das Coroas Ibéricas em 1580. O monarca também era exemplo de bom cristão por seu envolvimento nas lutas contra os muçulmanos, seja em seu próprio território (com novas leis que restringiam a liberdade dos mouriscos e que resultaram em revoltas entre 1568 e 1571 - Alpujarras) e fora da península (como a vitória em Lepanto, em 1571).

Essa narrativa dos feitos de Felipe II como exemplo de cristão se consolidava aliada ao reforço retórico da imagem do Escorial como expressão pétrea desse monarca piedoso. Os dois principais autores que conviveram com Felipe II durante a edificação desse monumento, Luis Cabrera de Córdoba e o frei José de Siguenza, já mencionado anteriormente, deixaram em seus escritos a construção da memória do Escorial aliada à imagem religiosa do monarca.

Luis Cabrera de Córdoba, escreveu duas obras de especial interesse para tratarmos do Escorial: um poema dedicado à São Lourenço, intitulado "Laurentina", e uma História do reinado de Felipe $\mathrm{II}^{10}$. Nesses textos, os grandes feitos do monarca se apresentavam na grandiosidade do Escorial como exemplo e convite à conversão cristã. Essa mensagem também é reforçada nos escritos de 
Siguenza, monge jerônimo e historiador da ordem, que escreveu uma História sobre a construção do Escorial em que a piedade dos monges e do próprio rei é parte da construção espiritual aliada à construção material desse edifício, pois um edifício religioso não se constrói apenas com pedras ${ }^{11}$. Os textos dos dois autores colocavam o Escorial como local em que a luta e a defesa do cristianismo ligado ao papa em Roma se apresentavam e se perpetuavam no tempo. Era um edifício para honra a Deus e sua providência agindo em favor de Felipe II.

Além da piedade dos reis de Judá, a escolha das estátuas que deveriam coroar a fachada da igreja reforçava a memória do Templo de Salomão, edifício em que a imagem da monarquia agindo como executora dos desejos divinos e da defesa da fé é apresentada de forma exemplar. Por isso, temos as imagens de Davi e Salomão ao centro, momento de maior glória desses reis, sendo Salomão foi o primeiro construtor do Templo de Jerusalém recebendo o modelo do próprio Deus, além de ser modelo de rei sábio e prudente, assim como a imagem de Felipe Il era constantemente apresentada. No lado do Evangelho da Basílica, que é hierarquicamente superior ao da Epístola, encontra-se a estátua de Davi, que, dessa forma, recebe maior importância na composição da fachada. Essa escolha pode estar associada à imagem do imperador Carlos V, governante belicoso, enquanto seu filho, mais pacífico, era lembrado como Salomão, que pode gozar da paz para edificar o templo. Essas duas imagens centrais tem ao lado os demais reis representados numa atitude de escolta. Assim Siguenza apresenta esse conjunto de esculturas:

David y Salomón, su hijo, como los principales e el reino y e la fabrica, están en el medio. Tiene David la mano derecha por ser padre, principio tambien del reino en santidade, sin segundo entre los Reyes, el primero que trató de edificar á Dios templo, el que mereció recibir las trazas de manos del Señor, y el que deó para su fabrica mayor suma de oro y plata que jamás se ha leido haya alcanzado otro Rey: la figura es excelente y de lindo ornato y movimento; muestra que está hablando con su hijo Salomon, que le escucha con modéstia; y porque cuando edificó el templo era mancebo, lo parece así en la figura: sin barba, hábito de pacífico y muy galano, símbolo admirable del Rey Eterno, Señor nuestro, lesucristo. ${ }^{12}$

Cabrera apresenta Davi deixando mais explícita sua belicosidade, ainda afirmando sua contribuição para o templo, mas dando ênfase aos motivos que fizeram apenas seu filho ser realmente digno dessa obra, o que também seria indicado por Siguenza em outras partes de seu texto ${ }^{13}$. Nas

\footnotetext{
11 SICUENZA, Jose de. Historia primitiva y exacta del Monasterio del Escorial. Madrid: Imprenta y Fundación de M. Tello, impressor de Cámara de S. M. Isabel la Católica, 1881. Fac-símile Valladolid: Editorial Maxtor, 2003.

12 Idem, p.270-271.

13 "David descubre por el manto la empunhadura de um descomunal alfange, como hombre de pelea y guerreiro, por lo que no quiso Dios que le edificase templo."
} 
palavras de Cabrera:

Fijardo está David al diestro lado,

porque los materiales ha traído

para el templo que el hijo ha edificado,

porque Dios que él le hiciese no ha querido,

que la inocente sangre ha derramado;

tiene su arpa y cetro esclarecido,

el denuedo mostrando en el semblante

con que la horrenda muerto dio al gigante. ${ }^{14}$

Siguenza afirma que a identificação dos reis deveria ser feita pelos atributos de cada um e que a escolha das imagens e a maneira de retratá-los tinha sido resultado das formulações de Benito Arias Montano (1527-1598) ${ }^{15}$, capelão de Felipe II e primeiro bibliotecário do Escorial. Cabrera considera que tal escolha também fora influenciado por Siguenza ${ }^{16}$.

David é representado como guerreiro, tendo em baixo de seu manto um alfanje e a harpa. Salomão tem um livro na mão esquerda, indicando que era homem sábio e que tinha escrito muitos textos e, segundo Siguenza, que "alcanzó más que todos los filósofos."17

Nas palavras de Cabrera, a reverência a Salomão também recebe destaque, pois é o célebre construtor desse templo:
á el primero, en la siniestra mano,
el sábio Salomón, hijo querido
del divino profeta soberano,
que el templo celebrado ha construido.
En potencia y saber no hombre humano,
sino del cielo al suelo conducido,
para mostrarnos Dios de su potencia
alguna partecilla en su sapiência. ${ }^{18}$

Josafá, tem na mão esquerda, segundo Siguenza, um instrumento de cortar lenha, porque tinha mandado destruir os bosques em que se adoravam outros deuses, o que fez com intenção de

\footnotetext{
Idem, p.271.

14 CABRERA DE CORDOBA, L. Laurentina. Edição de Lucrecia Perez Blanco. Madrid: Villena, 1975, p.157.

15 "El doctísimo Arias Motano, fué el inventor y por cuyo consejo, se pusieron las estátuas de estos seis Reyes;[...]"Hacen uma vista hermosísima y muestran uma randeza verdadeiramente Real".

SIGUENZA, J. Op. cit., p.272.

16 "prior que fue de aquel célebre y religioso convento, varon observante y eminete de todas letras y lenguas, y de no vulgar elocuencia em la española y latina"

CABRERA DE CÓRDOBA, L. Filipe Segundo, Rey de España. Madrid: Imprenta, Estereotipia y Galvanoplastia de Aribauy Ca , 1877, p. 63.

17 SICUENZA, J. Op. Cit., p.271.

18 CABRERA DE CÓRDOBA, L. Op. cit., p. 157
} 
restaurar a religião monoteísta de seus antepassados. É ali lembrado porque tentava retomar as leis divinas que tinham sido abandonadas por seu povo ${ }^{19}$. Ezequias, que teria restaurado o altar e os sacrifícios no templo, tinha como atributo uma naveta ${ }^{20}$.

Ao lado esquerdo de Salomão estava Josias, que é o único a trazer o cetro na mão esquerda e seu atributo, um livro, na mão direita, o que, segundo Siguenza, significava que "los Reyes santos más han de usar de la ley de Dios, que del cetro y del império."21.

Por fim, Manasés, tem como atributos uma régua e um compasso e nos pés a roupa que teria vestido no cativeiro na Babilônia. Retornando a seu reino, construiu um muro, por isso os atributos ${ }^{22}$.

Dessa forma, a ênfase estava na edificação do templo e na figura de Salomão, sendo os demais reis figuras que reforçavam a imagem do poder real, da dinastia, do poder dos governantes agindo na defesa do culto divino, da igreja física e da própria religião. A imagem desses reis era também uma das manifestações do esforço de cristianização da Antiguidade, valorizando as referências do Antigo Testamento no discurso sobre as obras realizadas sobre o patrocínio régio. Assim como os Reis da Antiguidade, a Monarquia Hispânica, encarnada na dinastia dos Habsburgos, era a expressão dos desejos divinos daqueles que deveriam conduzir o destino político de seus súditos e guiar com seus exemplos de fé para a salvação da alma dos fieis sob seu comando ${ }^{23}$.

O uso retórico da imagem do templo de Salomão para valorizar uma edificação realizada por um monarca não era uma novidade de Felipe II. Durante toda a Idade Média e Moderna esse era o modelo divino a se reproduzir. A dinastia que antecede Carlos V e Felipe II, os Trastâmaras, já utilizavam a iconografia salomônica para representar os reis espanhóis, entre eles Enrique II (c.1333-1379),

\footnotetext{
19 "Josafat tiene em la mano izquierda um asegur ó hacha de cortar leña, tambien de bronce dorado [...] para mostrar el instrumento com que mandó destruir aquellas arboledas y bosques de los dioses em que adoraba aquel Pueblo cielo, cuando perdió la verdadeira doctrina que tenia recibida del cielo, y procurando se practicase y enseñase la ley del Señor; y para significar esto, tiene tambien unos panes y um cabron junto á sí." SIGUENZA, J. Op. cit., p.272.

20 "Ezequias tiene uma naveta de oro y cabron junto á si, para sinificar la restauracion del altar y de los sacrifícios."

SIGUENZA, J. Op. cit., p.271.

21 SICUENZA, J. Op. cit., p.271-2.

22 "Segundo es Manasés, que encadenado

está para mostrar el cautiverio

que tuvo en Babilonia aprisionado,

haciendo a Israel gran vitupério.

Un compás de la diestra le ha colgado,

porque, libre que fue, vuelto a su império,

un fuerte muro en la cuidad fundara,

que de David el nombre conservara."

CABRERA DE CÓRDOBA, L. Op. cit., p. 158.

23 "De la misma manera que Dios nombraba a los reyes del Antiguo Testamento para que gobernasen a su pueblo, así España —nuevo «pueblo elegido»- es regida por sus reyes que son, a su vez, los defensores y valedores del catolicismo frente a sus enemigos."

CORNEJO, Francisco ]. Felipe II, San Hermenegildo y la imagem de la "Sacra Monarquía". In: Boletín del Museo del Prado, tomo 18. Madrid: Fundación Amigos del Museo del Prado, 2000, págs. 25-38, p.26.
} 
Juan I (1358-1390) e Enrique IV (1425-1474) 24

Siguenza compara o Escorial a três importantes edifícios realizados pelos homens sob o comando divino. O Escorial era como a Arca de Noé, pois em seu interior, pela oração e pelo exemplo de sua grandiosidade como demonstração da força divina, era um convite à conversão e à salvação das almas. O dilúvio era uma metáfora para a crise religiosa enfrentada com a quebra da unidade após as Reformas Religiosas. Era também como o Tabernáculo de Moisés, onde o próprio Deus vivia, reforçando assim a imagem de que a religião professada pelos monarcas era a correta e verdadeira em relação às novas possibilidades de se professar o cristianismo. Por fim, era o Templo de Salomão, edifício digno e que correspondia ao desejo divino sobre onde deveria ser honrado. Essas três referências buscavam validar as posições e ações de Felipe II naquele momento de disputas e rupturas, sendo claramente o Templo de Salomão a principal imagem a se reforçar, o que se dá logo na entrada da igreja.

Dessa maneira, o uso da imagem dos reis do Antigo Testamento buscava legitimar o cristianismo professado pelos monarcas espanhóis e era uma mensagem poderosa em um edifício que, em muitos aspectos, expressava uma resposta às Reformas Religiosas e aos conflitos gerados com a quebra da unidade religiosas na Europa em princípios da Idade Moderna. 


\section{Referências bibliográficas}

BOUZA ÁLVARES, Fernando ]. Imagen y propaganda. Capítulos de Historia Cultural del Reinado de Felipe II. Madrid: Akal, 1998.

CABRERA DE CORDOBA, Luis Laurentina. Edição de Lucrecia Perez Blanco. Madrid: Villena, 1975.

Filipe Segundo, Rey de España. Madrid: Imprenta, Estereotipia y Galvanoplastia de Aribauy Ca, 1877.

CORNEJO, Francisco ]. Felipe II, San Hermenegildo y la imagem de la "Sacra Monarquía". In: Boletín del Museo del Prado, tomo 18. Madrid: Fundación Amigos del Museo del Prado, 2000, págs. 25-38.

GARCIA-FRÍAS, C.; SANCHO, J.L. Real monastério de San Lorenzo de El Escorial. Madrid: Reales Sítios de España, 2010.

KANTOROWICZ, E. H. Os dois corpos do rei. Um estudo sobre teologia política medieval. Trad. Cid Knipel Moreira. São Paulo: Companhia das Letras, 1998.

MARTÍN GONZÁLEZ, J. J. Interacción: arquitectura y escultura en El Escorial. In: JAVIER CAMPOS Y FERNÁNDEZ DE SEVILLA, F. (coord.). La escultura en el Monasterio del Escorial: Actas del Simposium. Madrid: Real Centro Universitario Escorial-María Cristina, 1994, págs.31-57.

MARTÍNEZ PEÑAS, L; HERREROS CEPEDA, A. El desplazamiento de loso moriscos tras la rebelión de los Alpujarras: contexto político, estratégico y militar de uma migración forzosa. In: CARCÍA CASTAÑO, F.]. ; KRESSAVA, N. (coords.) Actas del Congreso Internacional sobre Migraciones en Andalucia. Granada: Instituto de Migraciones, p.2073-2082.

MÍNCUEZ , V. El rey de España se sienta en el trono de Salomón. Parentescos simbólicos entre la casa de David y la Casa de Austria. in: idem (ed.). Visiones de la monarquía hispânica. Castelló de la Plana: Publicacions de la Universitat Jaume I, 2007, págs.19-56

Introducción. De Dios y los reyes hispanos en la Edad Moderna. In: idem (ed.). Visiones de la monarquía hispânica. Castelló de la Plana: Publicacions de la Universitat Jaume I, 2007, págs. 9-16.

MUHANA, A.; LAUDANNA, M.; BAGOLIN, L. A. (orgs.). Retórica. São Paulo: Annablume, 2012.

SICUENZA, Jose de. Historia primitiva y exacta del Monasterio del Escorial. Madrid: Imprenta y Fundación de M. Tello, impressor de Cámara de S. M. Isabel la Católica, 1881. Fac-símile Valladolid: Editorial Maxtor, 2003.

WILKINSON-ZERNER, C. Juan de Herrera: Arquitecto de Felipe II. Trad. Isabel Balsinde. Madrid: Ediciones Akal, 1996. 